\title{
Development of Normal Tissue Complication Probability Model for Trismus in Head and Neck Cancer Patients Treated With Radiotherapy: The Role of Dosimetric and Clinical Factors
}

\author{
MASAHIRO MORIMOTO ${ }^{1,2,3}$, HENK P. BIJL ${ }^{1}$, ARJEN VAN DER SCHAAF ${ }^{1}$, \\ CHENG-JIAN XU ${ }^{1}$, ROEL J.H.M. STEENBAKKERS ${ }^{1}$, OLGA CHOUVALOVA ${ }^{1}$, \\ YASUO YOSHIOKA ${ }^{4}$, TERUKI TESHIMA ${ }^{3,5}$ and JOHANNES A. LANGENDIJK \\ ${ }^{1}$ Department of Radiation Oncology, University Medical Center Groningen, \\ University of Groningen, Groningen, the Netherlands; \\ ${ }^{2}$ Department of Radiation Oncology, Osaka University Graduate School of Medicine, Suita, Japan; \\ ${ }^{3}$ Department of Radiation Oncology, Osaka International Cancer Institute, Osaka, Japan; \\ ${ }^{4}$ Radiation Oncology Department, Cancer Institute Hospital of Japanese Foundation for Cancer Research, Tokyo, Japan; \\ ${ }^{5}$ Department of Medical Physics \& Engineering, Osaka University Graduate School of Medicine, Suita, Japan
}

\begin{abstract}
Background/Aim: The aim of this study was to develop a normal tissue complication probability (NTCP) model for trismus in head and neck cancer (HNC) patients treated with radiotherapy (RT). Patients and Methods: Prospective measurements of maximum inter-incisal opening (MIO) were performed at baseline and 6 months after definitive RT in 132 HNC patients. The primary endpoint of this study was defined when a patient fulfilled both of the following criteria: 1) MIO at 6 months after $R T \leq 35 \mathrm{~mm}$ and 2) MIO at 6 months after $R T \leq 80 \%$ of baseline MIO. Eleven clinical factors and a wide range of dosimetric factors (mean dose, maximum dose, V5, V10, V20, and V40) in twelve organs at risk (OARs) were chosen as candidate prognostic variables. Results: Thirty out of 132 patients (23\%) developed the primary endpoint. Multivariate logistic regression analysis revealed that the mean dose to the contralateral mandible joint $(p=0.001)$ and baseline MIO $(p=0.027)$ were independent prognostic factors. Conclusion: A multivariable NTCP model for trismus in HNC patients treated with RT was established including the mean dose to contralateral mandible joint and baseline MIO.
\end{abstract}

This article is freely accessible online.

Correspondence to: Masahiro Morimoto, Department of Radiation Oncology, University Medical Center Groningen, University of Groningen, P.O. Box 30001, 9700 RB Groningen, the Netherlands. Tel: +31 503615532, Fax: +31 503611692, e-mail: morimotoknk@umin.ac.jp

Key Words: Head and neck cancer, radiotherapy, trismus, normal tissue complication probability model, prediction.
Trismus after radical radiotherapy has a major impact on quality of life (QoL) of head and neck cancer (HNC) patients (1-4). Previous studies have shown that rehabilitation of radiation-induced trismus is difficult to treat (5-8). Trismus is considered to result from slowly progressive fibrosis of the mandible joints and muscles involved in mandibular movements (9-11). Some data exist on the relationship between dosimetric factors of organs at risk (OARs) and trismus in univariate analysis and multivariate analysis (1219). However, limited data exist on the relation among dosimetric factors of OARs, clinical factors, and trismus in multivariate analysis (20). Therefore, it remains unclear which risk OARs, dose-volume parameters and patient factors contribute most to the development of trismus. Therefore, identification of the most important prognostic factors and establishment of a multivariable prediction model for trismus is of major importance. Therefore, the aim of this prospective study was to develop a multivariable normal tissue complication probability (NTCP) model for trismus in $\mathrm{HNC}$ patients treated with RT using dosimetric and clinical factors by multivariate logistic regression analysis.

\section{Patients and Methods}

Patients and eligibility criteria. Between July 2007 and August 2010, 132 HNC patients who received definitive RT with or without systemic treatment at the department of Radiation Oncology of the UMCG were included in this retrospective analysis of prospectively collected data. All patients were subjected to the standardised follow-up program (SFP), as previously described (21), including a prospective evaluation of the maximum inter-incisal opening (MIO) routinely before and 6 months after curative (chemo-) radiotherapy (CH)RT. To be included in the analysis, patients had to fulfill the 
following eligibility criteria: 1) HNC originating in the oral cavity, nasopharynx, oropharynx, hypopharynx, or larynx; 2) treated with definitive RT either alone or in combination with chemotherapy or cetuximab; 3) no previous surgery, RT and/or chemotherapy; 4) no previous malignancies; 5) no distant metastases; 6) planningcomputed tomography (CT) and three-dimensional dose distributions available prior to and 6 months after completion of $(\mathrm{CH}) \mathrm{RT}$; 7) no efforts of reducing dose in potential organs at risks (OARs) for trismus; 8) alive with no recurrences 6 months after RT, and: 9) no rehabilitation or medication for trismus. The study population used for this analysis was composed of 132 patients who fulfilled all these eligibility criteria. The majority of the patients were male (77\%) and the mean age of the study population was 62 years, ranging from 33 to 89 years. The number of the patients treated with concurrent systemic therapy was $40(30 \%)$. The demographic and tumor characteristics of this study population are listed in Table I.

Endpoints. MIO, was assessed using a commercially available device named Terabyte ${ }^{\circledR}$ (Atos Medical, Hörby, Sweden). In patients with an edentulous maxilla and not wearing dentures, the distance between the incisal edge of the alveolar ridge in the mandibular central incisor of the right (location 41) and that in the maxillary central incisor of the right (location 11) can be measured. In edentulous patients wearing dentures, the distance between the upper and lower dentures (location 41 and 11) can be measured

To evaluate trismus due to RT, MIO was measured at baseline and at 6 months after RT. The 6 months interval was chosen because radiation-induced trismus usually becomes apparent between 3 and 6 months after completion of RT (22).

Trismus, the primary endpoint of this study, was defined when a patient fulfilled both following criteria:

1) MIO at six months after RT $\leq 35 \mathrm{~mm}$,

2) MIO at six months after RT $\leq 80 \%$ of baseline MIO.

The first criterion was chosen because it demonstrated the most significant cut-off point of trismus in a previous study and is considered clinically relevant (23). The second criterion was chosen because the mean MIO at 6 months after RT was $80 \%$ of that of baseline by the report of Wang et al. (24). In the first diagnosis, some patient's MIO was less than or equal to $35 \mathrm{~mm}$. Therefore, the second criterion was needed based on the reference.

Treatment. RT was delivered with linear accelerators (LINIAC) using megavoltage equipment. In all patients, a planning $\mathrm{CT}$ scan was made in supine position. All patients were treated with three dimensional conformal RT (3D-CRT) or intensity modulated radiation therapy (IMRT). Patient position was fixed with a fivepoint individual thermoplastic mask (Posicast ${ }^{\circledR}$ thermoplastics, CIVICO, Orange, IA, USA) in combination with a standard head support (Posifix ${ }^{\circledR}$ supine headrest, CIVICO). Position verification was carried out by using a shrinking action level correction protocol (SAL-protocol), using an electronic portal imaging device (EPID). Patients with early glottic cancer were treated with a fractionation dose of 2.5 Gy ( 5 times/week) up to a total dose of 60 Gy in 5 weeks or with a fraction dose of $2.0 \mathrm{~Gy}$ ( 5 or 6 times/week) up to a total dose of $66 \mathrm{~Gy}$. These patients were only irradiated at the primary site. The 26 laryngeal cancer patients received local therapy. Their data are an important part of this study as a control,
Table I. Patients characteristics and treatment parameters.

\begin{tabular}{|c|c|}
\hline \multicolumn{2}{|l|}{ Age } \\
\hline Median (years) & 62 \\
\hline Range & $33-89$ \\
\hline \multicolumn{2}{|l|}{ Gender } \\
\hline Male & 102 \\
\hline Female & 30 \\
\hline \multicolumn{2}{|l|}{ Site } \\
\hline Oral cavity & 4 \\
\hline Nasopharynx & 2 \\
\hline Oropharynx & 43 \\
\hline Hypopharynx & 15 \\
\hline Larynx & 68 \\
\hline \multicolumn{2}{|l|}{ Tumor classification } \\
\hline $\mathrm{T} 1$ & 19 \\
\hline $\mathrm{T} 2$ & 53 \\
\hline $\mathrm{T} 3$ & 27 \\
\hline $\mathrm{T} 4$ & 33 \\
\hline \multicolumn{2}{|l|}{ Node classification } \\
\hline No & 62 \\
\hline N1 & 15 \\
\hline $\mathrm{N} 2 \mathrm{a}$ & 3 \\
\hline $\mathrm{N} 2 \mathrm{~b}$ & 11 \\
\hline $\mathrm{N} 2 \mathrm{c}$ & 39 \\
\hline N3 & 2 \\
\hline \multicolumn{2}{|l|}{ Stage } \\
\hline I & 14 \\
\hline II & 45 \\
\hline III & 14 \\
\hline IV & 59 \\
\hline \multicolumn{2}{|l|}{ Histology } \\
\hline Squamous cell carcinoma & 130 \\
\hline Undifferentiated large cell carcinoma & 2 \\
\hline \multicolumn{2}{|l|}{ Baseline maximum inter-incisal opening } \\
\hline Median (mm) & 42 \\
\hline Range & $19-70$ \\
\hline \multicolumn{2}{|l|}{ Fractionation } \\
\hline Conventional & 37 \\
\hline Accelerated & 95 \\
\hline \multicolumn{2}{|l|}{ Bilateral neck irradiation } \\
\hline Yes & 99 \\
\hline No & 33 \\
\hline \multicolumn{2}{|l|}{ Chemotherapy or Cetuximab } \\
\hline Yes & 40 \\
\hline No & 92 \\
\hline
\end{tabular}

although their OARs for trismus did not receive a significant dose. Patients treated with concomitant CHRT were treated with conventional fractionation (2.0 Gy per fraction, 5 times per week up to $70 \mathrm{~Gy}$ in 7 weeks). In case of primary RT of the more advanced cases, which were considered not eligible for CHRT, an accelerated schedule with concomitant boost technique was used, either or not combined with cetuximab. These patients were generally treated with 6 fractions per week with a second fraction on Friday afternoon with minimum interval of $6 \mathrm{~h}$, up to a total dose of $70 \mathrm{~Gy}$ in 6 weeks. Most of the patients received bilateral elective irradiation of the neck nodes to a total dose of $46 \mathrm{~Gy}$ and a boost on the primary tumor and swelling lymph nodes to a total dose of $70 \mathrm{~Gy}$. 
Contouring of organs at risk. OARs potentially related to trismus were delineated according to an institutional atlas and according to the report by Teguh et al. (12) including the ipsilateral and contralateral medial pterygoid muscles, lateral pterygoid muscles, masseter muscles, mandible joints, mandible joints $+5 \mathrm{~mm}$, and temporal muscles. OARs were delineated by radiation oncologists (M. $\mathrm{M}$ and HP. B). The dose-volume parameters (mean dose, maximum dose, V5, V10, V20, and V40) in each OARs were extracted.

Statistics. Pearson correlation matrixes were produced twice (Table II and Figure 1) in order to check for high correlation between potential prognostic determinants. In case of high Pearson correlation coefficients, these variables were reduced to avoid the problem of multicollinearity, which may negatively affect the generalizability of the model. Table II was used to decide the representative dose-volume parameter of each OARs. Figure 1 was used to decide the clinical factors and the dosimetric factors for univariate regression analysis.

Next, the variables after the reference of Pearson correlation matrixes (Table II and Figure 1) initially included in the univariate logistic regression model are shown in Table III. Then, a multivariate logistic regression analysis was carried out including only variables that were significant in the univariate logistic regression model. For each patient, predictive values (i.e., NTCP values) were calculated for each set of prognostic variables based on the regression coefficients according to the formula:

$$
\begin{gathered}
\text { NTCP }=\left(1+\mathrm{e}^{-5}\right)^{-1} \text {, where } \\
S=\beta_{0}+\sum_{i=1}^{n} \beta i \cdot X i
\end{gathered}
$$

\section{Results}

Prevalence of trismus. At 6 months after completion of treatment, 30 out of 132 patients $(23 \%)$ showed trismus six months after RT.

Variable selection procedure and NTCP models for trismus. We produced the first Pearson correlation matrix to identify the dose-volume parameters of all OARs that were strongly (Pearson correlation coefficient $\geq 0.8$ ) or moderately (Pearson correlation coefficient $\geq 0.7$ ) correlated (Table II). Strong or moderate correlation was observed among many dosevolume parameters within each OAR. Therefore, we decided to make the mean dose of each OARs represent the dosevolume parameters of each OARs, while the V5, V10, V20, V40 and maximum dose of each OARs were excluded from further analyses. The mean dose, in general, showed good correlations with other dose-volume parameters. We decided to not enter the mean dose to temporal muscles in the second Pearson correlation matrix, because the average of the mean doses to the ipsilateral and contralateral temporal muscles was relatively low, i.e., only $4.4 \mathrm{~Gy}$ and 3.6 Gy, respectively, and not expected to be important.

Next, the variables (which were reduced by the above procedure) with the second Pearson correlation matrix are shown in Figure 1. We selected the variables that showed less than four very strong correlations (Pearson correlation coefficient $\geq 0.85$ ) for the univariate regression analysis. Eventually, clinical factors and three dosimetric factors, including the mean doses to contralateral mandible joint, contralateral masseter muscle and the ipsilateral medial pterygoid muscle were selected for entering the univariate regression analysis.

In the univariate logistic regression analysis (Table III), all three dosimetric factors showed a significant association with trismus. In addition, conventional RT [versus (vs.) accelerated RT], oral cavity, nasopharyngeal, oropharyngeal, or hypopharyngeal cancer (vs. laryngeal cancer), N2b-3 (vs. N0-2a), female ( $v s$. male), Stage III-IV ( $v s$. Stage I-II), and systemic therapy + RT ( vs. RT alone) and baseline MIO were also significant factors associated with trismus in the univariate analysis.

A multivariate logistic regression analysis was carried out including only the significant variables shown above in the univariate logistic regression analysis. The multivariate regression analysis eventually revealed two independent prognostic factors, including the mean dose to the contralateral mandible joint and baseline MIO. The average Dmean to the contralateral mandible joint in patients with trismus was 18 Gy [95\% confidence interval $(\mathrm{CI})=12.4-23.6$ Gy], which was significantly higher than that observed among those without trismus, which was $7.7 \mathrm{~Gy}(95 \% \mathrm{CI}=5.8$ $9.7 \mathrm{~Gy})(t$-test: $p=0.001)$. The average baseline MIO among patients with trismus was $38.3 \mathrm{~mm}(95 \% \mathrm{CI}=35.4-41.3 \mathrm{~mm})$, which was significantly lower compared to that observed among those without trismus, which was $43.2 \mathrm{~mm}$ (95\%CI=41.4-44.9 mm) ( $t$-test: $p=0.008)$. The distribution of all 132 mean doses to the contralateral mandible joint and baseline MIO are shown in Table IV. The NTCP-value for each variable is shown in Table $\mathrm{V}$. The bar graph of the NTCP model based on the two variables and the quick reference are shown in Figure 2 and Figure 3, respectively. The goodness of fit of this model was confirmed in Hosmer and Lemeshow test $(p=0.182)$. The calibration of this model is shown in Figure 4 and confirmed the goodness of fit of this model. The NTCP-value for each individual patient can be calculated by the following regression formula:

$\mathrm{NTCP}=\left(1+\mathrm{e}^{-s}\right)^{-1}$, where

$S=0.494+[$ Mean dose to contralateral mandible joint (Gy) $\times 0.061]+[$ Baseline MIO $(\mathrm{mm}) \times(-0.06)]$

\section{Discussion}

The innovation and intensification of RT techniques and schedules together with the addition of systemic treatment has led to improved prognosis of HNC (25-30). Consequently, the prevalence of patients suffering from late toxicity is rising 
Table II. The first Pearson correlation matrix of the dosimetric factors (mean dose, maximum dose, V5, V10, V20 and V40) of the twelve organs at risk $(O A R s)$. Strong $(\geq 0.8)$ and moderate $(\geq 0.7)$ correlations are shown in bold and italics, respectively. The mean dose in each OARs was chosen for the representative of each OARs, while the maximum dose, V5, V10, V20 and V40 of each OARs were excluded from further analyses.

\begin{tabular}{|c|c|c|c|c|c|c|}
\hline \multirow{2}{*}{$\begin{array}{l}\text { Ipsilateral } \\
\text { mandible joint }\end{array}$} & \multicolumn{6}{|c|}{ Ipsilateral mandible joint } \\
\hline & Mean dose & Maximum dose & V5 & $\mathrm{V} 10$ & V20 & V40 \\
\hline Mean dose & 1 & 0.957 & 0.762 & 0.832 & 0.912 & 0.808 \\
\hline Maximum dose & 0.957 & 1 & 0.868 & 0.911 & 0.898 & 0.671 \\
\hline V5 & 0.762 & 0.868 & 1 & 0.919 & 0.713 & 0.341 \\
\hline V10 & 0.832 & 0.911 & 0.919 & 1 & 0.827 & 0.406 \\
\hline V20 & 0.912 & 0.898 & 0.713 & 0.827 & 1 & 0.597 \\
\hline V40 & 0.808 & 0.671 & 0.341 & 0.406 & 0.597 & 1 \\
\hline \multirow{2}{*}{$\begin{array}{l}\text { Contralateral } \\
\text { mandible joint }\end{array}$} & \multicolumn{6}{|c|}{ Contralateral mandible joint } \\
\hline & Mean dose & Maximum dose & V5 & V10 & V20 & V40 \\
\hline Mean dose & 1 & 0.968 & 0.755 & 0.851 & 0.906 & 0.757 \\
\hline Maximum dose & 0.968 & 1 & 0.761 & 0.848 & 0.859 & 0.677 \\
\hline V5 & 0.755 & 0.761 & 1 & 0.843 & 0.597 & 0.295 \\
\hline V10 & 0.851 & 0.848 & 0.843 & 1 & 0.767 & 0.380 \\
\hline V20 & 0.906 & 0.859 & 0.597 & 0.767 & 1 & 0.623 \\
\hline V40 & 0.757 & 0.677 & 0.295 & 0.380 & 0.623 & 1 \\
\hline \multirow{2}{*}{$\begin{array}{l}\text { Ipsilateral mandible } \\
\text { joint }+5 \mathrm{~mm}\end{array}$} & \multicolumn{6}{|c|}{ Ipsilateral mandible joint $+5 \mathrm{~mm}$} \\
\hline & Mean dose & Maximum dose & V5 & V10 & V20 & V40 \\
\hline Mean dose & 1 & 0.911 & 0.804 & 0.872 & 0.947 & 0.860 \\
\hline Maximum dose & 0.911 & 1 & 0.938 & 0.938 & 0.886 & 0.635 \\
\hline V5 & 0.804 & 0.938 & 1 & 0.948 & 0.790 & 0.439 \\
\hline V10 & 0.872 & 0.938 & 0.948 & 1 & 0.897 & 0.524 \\
\hline V20 & 0.947 & 0.886 & 0.790 & 0.897 & 1 & 0.726 \\
\hline V40 & 0.860 & 0.635 & 0.439 & 0.524 & 0.726 & 1 \\
\hline \multirow{2}{*}{$\begin{array}{l}\text { Contralateral mandible } \\
\text { joint }+5 \mathrm{~mm}\end{array}$} & \multicolumn{6}{|c|}{ Contralateral mandible joint $+5 \mathrm{~mm}$} \\
\hline & Mean dose & Maximum dose & V5 & $\mathrm{V} 10$ & V20 & V40 \\
\hline Mean dose & 1 & 0.932 & 0.806 & 0.903 & 0.939 & 0.788 \\
\hline Maximum dose & 0.932 & 1 & 0.867 & 0.919 & 0.859 & 0.602 \\
\hline V5 & 0.806 & 0.867 & 1 & 0.885 & 0.661 & 0.374 \\
\hline V10 & 0.903 & 0.919 & 0.885 & 1 & 0.836 & 0.495 \\
\hline V20 & 0.939 & 0.859 & 0.661 & 0.836 & 1 & 0.727 \\
\hline V40 & 0.788 & 0.602 & 0.374 & 0.495 & 0.727 & 1 \\
\hline \multirow{2}{*}{$\begin{array}{l}\text { Ipsilateral } \\
\text { temporal muscle }\end{array}$} & \multicolumn{6}{|c|}{ Ipsilateral temporal muscle } \\
\hline & Mean dose & Maximum dose & V5 & V10 & V20 & V40 \\
\hline Mean dose & 1 & 0.758 & 0.954 & 0.980 & 0.980 & 0.925 \\
\hline Maximum dose & 0.758 & 1 & 0.784 & 0.716 & 0.668 & 0.567 \\
\hline V5 & 0.954 & 0.784 & 1 & 0.975 & 0.924 & 0.789 \\
\hline V10 & 0.980 & 0.716 & 0.975 & 1 & 0.979 & 0.875 \\
\hline V20 & 0.980 & 0.668 & 0.924 & 0.979 & 1 & 0.938 \\
\hline V40 & 0.925 & 0.567 & 0.789 & 0.875 & 0.938 & 1 \\
\hline
\end{tabular}


Table II. Continued

\begin{tabular}{|c|c|c|c|c|c|c|}
\hline \multirow{2}{*}{$\begin{array}{l}\text { Contralateral } \\
\text { temporal muscle }\end{array}$} & \multicolumn{6}{|c|}{ Contralateral temporal muscle } \\
\hline & Mean dose & Maximum dose & V5 & V10 & $\mathrm{V} 20$ & V40 \\
\hline Mean dose & 1 & 0.788 & 0.961 & 0.969 & 0.957 & 0.773 \\
\hline Maximum dose & 0.788 & 1 & 0.796 & 0.701 & 0.632 & 0.533 \\
\hline V5 & 0.961 & 0.796 & 1 & 0.954 & 0.887 & 0.639 \\
\hline $\mathrm{V} 10$ & 0.969 & 0.701 & 0.954 & 1 & 0.967 & 0.669 \\
\hline V20 & 0.957 & 0.632 & 0.887 & 0.967 & 1 & 0.759 \\
\hline V40 & 0.773 & 0.533 & 0.639 & 0.669 & 0.759 & 1 \\
\hline \multirow{2}{*}{$\begin{array}{l}\text { Ipsilateral } \\
\text { masseter muscle }\end{array}$} & \multicolumn{6}{|c|}{ Ipsilateral masseter muscle } \\
\hline & Mean dose & Maximum dose & V5 & V10 & $\mathrm{V} 20$ & V40 \\
\hline Mean dose & 1 & 0.852 & 0.874 & 0.912 & 0.956 & 0.942 \\
\hline Maximum dose & 0.852 & 1 & 0.923 & 0.893 & 0.870 & 0.704 \\
\hline V5 & 0.874 & 0.923 & 1 & 0.984 & 0.931 & 0.688 \\
\hline $\mathrm{V} 10$ & 0.912 & 0.893 & 0.984 & 1 & 0.970 & 0.748 \\
\hline V20 & 0.956 & 0.870 & 0.931 & 0.970 & 1 & 0.837 \\
\hline V40 & 0.942 & 0.704 & 0.688 & 0.748 & 0.837 & 1 \\
\hline \multirow{2}{*}{$\begin{array}{l}\text { Contralateral } \\
\text { masseter muscle }\end{array}$} & \multicolumn{6}{|c|}{ Contralateral masseter muscle } \\
\hline & Mean dose & Maximum dose & V5 & V10 & $\mathrm{V} 20$ & $\mathrm{~V} 40$ \\
\hline Mean dose & 1 & 0.862 & 0.888 & 0.936 & 0.963 & 0.843 \\
\hline Maximum dose & 0.862 & 1 & 0.855 & 0.845 & 0.820 & 0.649 \\
\hline V5 & 0.888 & 0.855 & 1 & 0.958 & 0.877 & 0.555 \\
\hline $\mathrm{V} 10$ & 0.936 & 0.845 & 0.958 & 1 & 0.953 & 0.621 \\
\hline V20 & 0.963 & 0.820 & 0.877 & 0.953 & 1 & 0.717 \\
\hline V40 & 0.843 & 0.649 & 0.555 & 0.621 & 0.717 & 1 \\
\hline \multirow{2}{*}{$\begin{array}{l}\text { Ipsilateral medial } \\
\text { pterygoid muscle }\end{array}$} & \multicolumn{6}{|c|}{ Ipsilateral medial pterygoid muscle } \\
\hline & Mean dose & Maximum dose & V5 & V10 & V20 & $\mathrm{V} 40$ \\
\hline Mean dose & 1 & 0.891 & 0.905 & 0.935 & 0.955 & 0.979 \\
\hline Maximum dose & 0.891 & 1 & 0.956 & 0.938 & 0.916 & 0.857 \\
\hline V5 & 0.905 & 0.956 & 1 & 0.993 & 0.975 & 0.889 \\
\hline $\mathrm{V} 10$ & 0.935 & 0.938 & 0.993 & 1 & 0.994 & 0.924 \\
\hline V20 & 0.955 & 0.916 & 0.975 & 0.994 & 1 & 0.949 \\
\hline V40 & 0.979 & 0.857 & 0.889 & 0.924 & 0.949 & 1 \\
\hline \multirow{2}{*}{$\begin{array}{l}\text { Contralateral medial } \\
\text { pterygoid muscle }\end{array}$} & \multicolumn{6}{|c|}{ Contralateral medial pterygoid muscle } \\
\hline & Mean dose & Maximum dose & V5 & $\mathrm{V} 10$ & V20 & V40 \\
\hline Mean dose & 1 & 0.887 & 0.849 & 0.917 & 0.962 & 0.969 \\
\hline Maximum dose & 0.887 & 1 & 0.896 & 0.906 & 0.894 & 0.821 \\
\hline V5 & 0.849 & 0.896 & 1 & 0.955 & 0.874 & 0.769 \\
\hline $\mathrm{V} 10$ & 0.917 & 0.906 & 0.955 & 1 & 0.951 & 0.857 \\
\hline V20 & 0.962 & 0.894 & 0.874 & 0.951 & 1 & 0.941 \\
\hline V40 & 0.969 & 0.821 & 0.769 & 0.857 & 0.941 & 1 \\
\hline
\end{tabular}


Table II. Continued

\begin{tabular}{|c|c|c|c|c|c|c|}
\hline \multirow{2}{*}{$\begin{array}{l}\text { Ipsilateral lateral } \\
\text { pterygoid muscle }\end{array}$} & \multicolumn{6}{|c|}{ Ipsilateral lateral pterygoid muscle } \\
\hline & Mean dose & Maximum dose & V5 & V10 & V20 & V40 \\
\hline Mean dose & 1 & 0.901 & 0.870 & 0.923 & 0.956 & 0.964 \\
\hline Maximum dose & 0.901 & 1 & 0.953 & 0.931 & 0.901 & 0.811 \\
\hline V5 & 0.870 & 0.953 & 1 & 0.965 & 0.914 & 0.741 \\
\hline V10 & 0.923 & 0.931 & 0.965 & 1 & 0.978 & 0.820 \\
\hline V20 & 0.956 & 0.901 & 0.914 & 0.978 & 1 & 0.888 \\
\hline V40 & 0.964 & 0.811 & 0.741 & 0.820 & 0.888 & 1 \\
\hline \multirow{2}{*}{$\begin{array}{l}\text { Contralateral lateral } \\
\text { pterygoid muscle }\end{array}$} & \multicolumn{6}{|c|}{ Contralateral lateral pterygoid muscle } \\
\hline & Mean dose & Maximum dose & V5 & V10 & V20 & V40 \\
\hline Mean dose & 1 & 0.915 & 0.810 & 0.896 & 0.948 & 0.906 \\
\hline Maximum dose & 0.915 & 1 & 0.901 & 0.929 & 0.897 & 0.726 \\
\hline V5 & 0.810 & 0.901 & 1 & 0.925 & 0.819 & 0.547 \\
\hline V10 & 0.896 & 0.929 & 0.925 & 1 & 0.945 & 0.658 \\
\hline V20 & 0.948 & 0.897 & 0.819 & 0.945 & 1 & 0.789 \\
\hline V40 & 0.906 & 0.726 & 0.547 & 0.658 & 0.789 & 1 \\
\hline
\end{tabular}

and becomes increasingly relevant. Xerostomia and dysphagia have been considered as the representative toxicities affecting QoL (31-33). However, recently it has been shown that trismus may affect QoL in HNC patients as well (1-4). Morimoto et al. recorded that the prevalence of trismus after RT was $13 \%$ in Japanese HNC patients. The prevalence ranges from $5 \%$ to $50 \%$ (34-43). In the current study, the prevalence was within this range.

Fibrosis of the mandible joints and/or muscles involved in mouth opening is considered as the main cause of radiationinduced trismus. The mandible joint is covered with a capsule and divided into the upper and lower joint cavity by the articular disk. The articular disk consists of fibrocartilage. While opening the mouth, depression (hinge motion in lower joint cavity) and protrusion (sliding motion in upper joint cavity) in the mandible joint take place simultaneously (44). Movement of the mandible joint is extremely sensitive to relative minor changes of the anatomy and therefore this complicated movement could be disturbed by fibrosis of the irradiated mandible joint. This hypothesis is further confirmed by the findings of magnetic resonance imaging (MRI) in patients with trismus, which demonstrated muscle fibrosis, mandible joint, mandibular condyle sclerosis, mandibular ramus signal change, and joint capsular thickening (45). Fibroblasts, which may normally serve as the primary collagenproducing cells, are responsible for excess extracellular matrix collagen production, which may eventually lead to loss of smooth movement of the mandible joint. In chronic inflammation by irradiation, tumor necrosis factor alpha
( $\mathrm{TNF} \alpha$ ) expression has been shown to be involved in the activation of macrophages in injured tissue, which leads to the release of downstream fibrogenic cytokines. These cytokines include fibroblast growth factor 2 (FGF2) and transforming growth factor beta 1 (TGF $\beta 1)$. FGF2 is chemotactic and mitotic for fibroblasts, whereas TGF $\beta 1$ stimulates fibroblast proliferation and premature end-differentiation (9).

There are some studies on the relationship between trismus and dosimetric factors of OARs. Teguh et al. showed a significant correlation between the mean dose to the masseter muscles and the pterygoid muscles with trismus (12). Goldstein et al. found a linear relationship between dose to mandible joint and pterygoid muscle and MIO. In that study, functional impairment of the mandible joint already appeared at a relatively low dose level (from 14.9 Gy) (13). These investigators reported that in the univariate analysis the dose to pterygoid muscle, masseter muscle or mandibular joint was significantly associated with trismus.

The five reports demonstrated a significant dose-effect relationship between ipsilateral masseter or pterygoid muscle and trismus in the multivariate analysis (14-18). The three reports demonstrated that the clinical factors; tumor location, gender, baseline MIO, baseline age, dentition, free soft tissue transfer after surgery, reirradiation, chemotherapy, natural logarithm of time post-RT, and overall treatment time of RT correlated with trismus in multivariate analysis $(43,46,47)$.

Using dosimetric and clinical factors, Kraaijenga et al. recently reported that the NTCP model was established by the mean dose to ipsilateral masseter muscle, the mean dose 


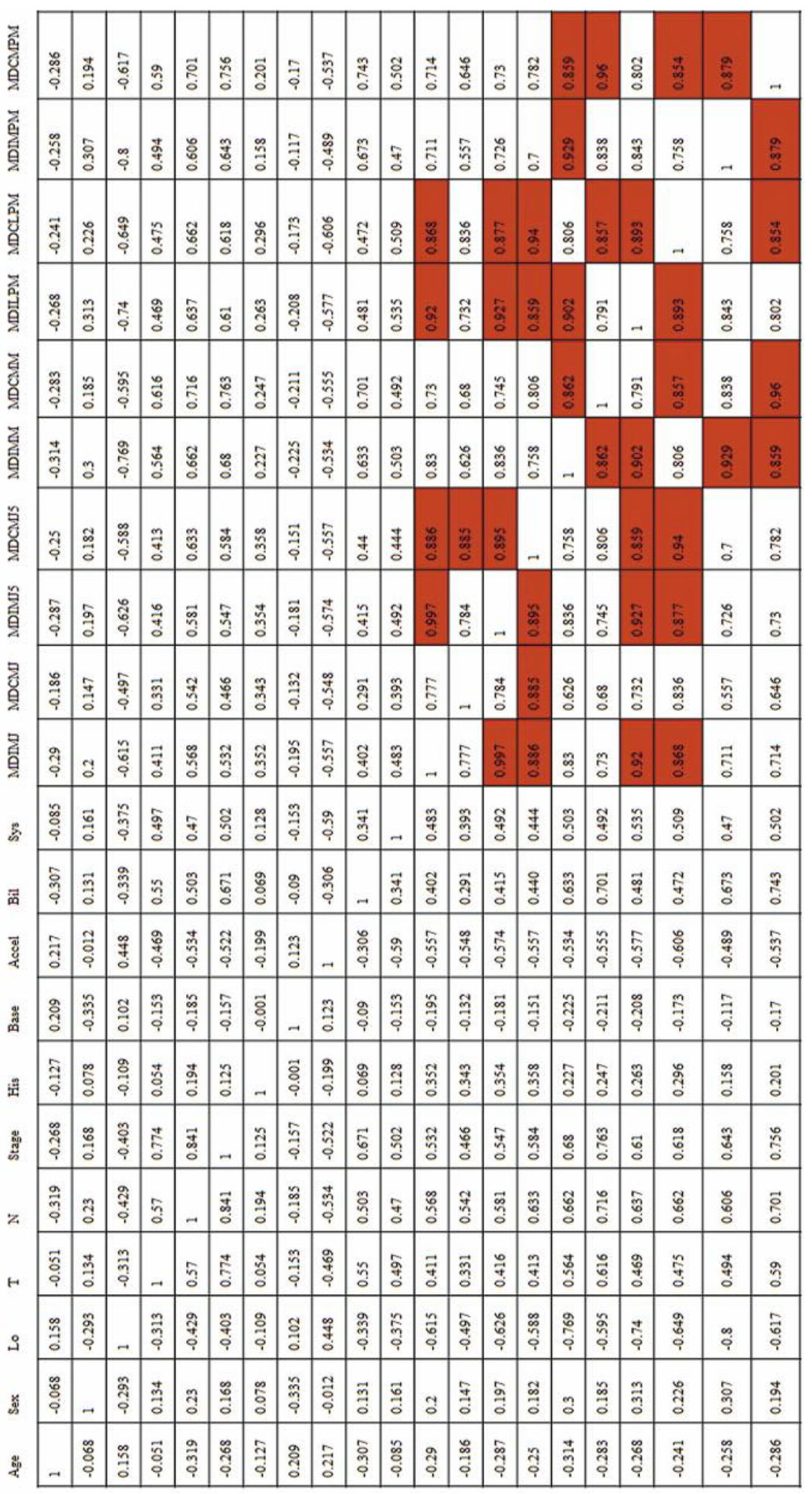

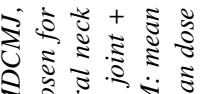

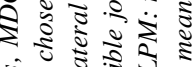

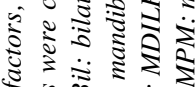
然范范 ป气

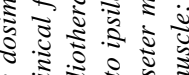

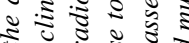

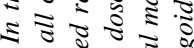
ชิ

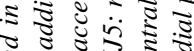
盖 8. के के

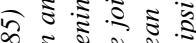
के

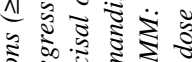
है.

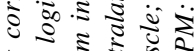
ㅇำ ล)

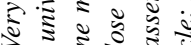

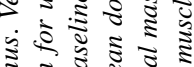
密 ㅇํㄹ के o :

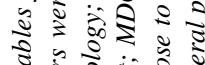
के $\frac{3}{8}$.

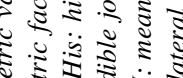

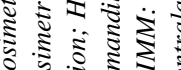
ช क ट รั)

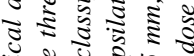

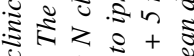

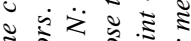

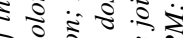

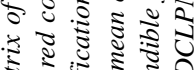

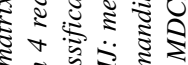

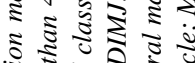

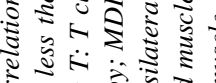

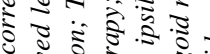

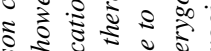

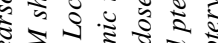

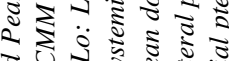

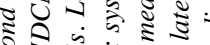

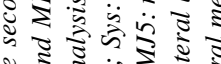

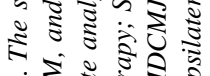
品ง 
Table III. Univariate logistic regression analysis of candidate prognostic variables for trismus after Pearson correlation matrixes (Table II and Figure 1).

\begin{tabular}{|c|c|c|c|c|c|}
\hline Predictor & $\beta$ & Odds ratio & $95 \% \mathrm{CI}$ & $p$-Value & AUC \\
\hline Age & -0.04 & 0.96 & $0.93-1.00$ & 0.07 & 0.61 \\
\hline Female vs. male & 1.07 & 2.91 & $1.20-7.10$ & 0.018 & 0.61 \\
\hline $\begin{array}{l}\text { Oral cavity, nasopharyngeal, oropharyngeal or } \\
\text { hypopharyngeal cancer } v s \text {. laryngeal cancer }\end{array}$ & 1.59 & 4.89 & $1.92-12.44$ & 0.001 & 0.68 \\
\hline $\mathrm{T} 3$ or $\mathrm{T} 4 v s . \mathrm{T} 1$ or $\mathrm{T} 2$ & 0.59 & 1.79 & $0.79-4.08$ & 0.163 & 0.57 \\
\hline $\mathrm{N} 2 \mathrm{~b}, \mathrm{~N} 2 \mathrm{c}$ or $\mathrm{N} 3$ vs. $\mathrm{N} 0, \mathrm{~N} 1$ or $\mathrm{N} 2 \mathrm{a}$ & 1.28 & 3.61 & $1.54-8.46$ & 0.003 & 0.66 \\
\hline Stage III or Stage IV $v s$. Stage I or Stage II & 1.23 & 3.42 & $1.35-8.67$ & 0.01 & 0.64 \\
\hline Undifferentiated large cell carcinoma $v s$. squamous cell carcinoma & 1.25 & 3.50 & $0.21-57.41$ & 0.383 & 0.51 \\
\hline Maximum inter-incisal opening & -0.07 & 0.94 & $0.89-0.98$ & 0.01 & 0.67 \\
\hline Conventional radiotherapy $v s$. accelerated radiotherapy & 1.68 & 5.36 & $2.20-12.80$ & $<0.001$ & 0.69 \\
\hline Bilateral neck radiotherapy $v s$. local or ipsilateral neck radiotherapy & 0.95 & 2.58 & $0.83-8.05$ & 0.1 & 0.58 \\
\hline Systemic therapy with radiotherapy $v s$. radiotherapy alone & 1.50 & 4.49 & $1.90-10.60$ & 0.001 & 0.67 \\
\hline Mean dose to ipsilateral medial pterygoid muscle & 0.03 & 1.03 & $1.01-1.06$ & 0.001 & 0.73 \\
\hline Mean dose to contralateral masseter muscle & 0.05 & 1.05 & $1.02-1.09$ & $<0.001$ & 0.70 \\
\hline Mean dose to contralateral mandible joint & 0.06 & 1.07 & $1.03-1.10$ & $<0.001$ & 0.75 \\
\hline
\end{tabular}

CI: Confidence interval; AUC: area under the curve; vs.: versus.

to ipsilateral medial pterygoid muscle, and the baseline MIO (20). Thus, limited data exist on the relation among dosimetric factors of OARs, clinical factors, and trismus in a multivariate NTCP model.

In the current study, the mean dose to contralateral mandible joint and baseline MIO were independent prognostic factors for trismus in the multivariate analysis. In addition, the NTCP model for trismus after RT was established with these two variables. Baseline MIO should be noted that it may be related to our definition of trismus. It might not be intuitive that mean dose to contralateral mandible joint was more significant than those of the ipsilateral masseter or the pterygoid muscle mentioned above. One possible reason for why the mean dose to the mandible joint was more important than that to other OARs is that the joint tissues are more sensitive to radiation induced-damage and/or that movement of the mandible joint is more complicated than muscle function, and are thus more prone to the effects of a lower dose (13). In addition, it could be hypothesized that the contralateral mandible joint played the most important role as this joint is the main compensator for trismus in the long-term process of fibrosis. We would like to emphasize that, to the best of our knowledge, this study is a unique prospective research that detected the significant clinical and dosimetric factors related to trismus using an actual measurement of MIO with multiple logistic regression analysis.

In order to avoid or improve trismus in HNC survivors, some strategies may be considered. First, based on the results of the current studies, constraint for the contralateral mandible joint could be employed, which may be different among individual patients based on their baseline MIO. For example, in a patient with a baseline MIO of $40 \mathrm{~mm}$, the
Table IV. Distributions of the mean dose to the contralateral mandible joint and the baseline maximum inter-incisal opening.

\begin{tabular}{lrcc}
\hline Variable & $\mathrm{n}$ & $\begin{array}{c}\text { With trismus } \\
(\mathrm{n}=30)\end{array}$ & $\begin{array}{c}\text { Without trismus } \\
(\mathrm{n}=102)\end{array}$ \\
\hline $\begin{array}{l}\mathrm{D}_{\text {mean }} \text { to the contralateral } \\
\text { mandible joint (Gy) }\end{array}$ & & & \\
0 to 10 & 88 & $12(40 \%)$ & $76(75 \%)$ \\
10 to 20 & 20 & $7(23 \%)$ & $13(13 \%)$ \\
20 to 40 & 18 & $7(23 \%)$ & $11(11 \%)$ \\
40 to 60 & 6 & $4(13 \%)$ & $2(2 \%)$ \\
Baseline maximum & & & \\
inter-incisal opening (mm) & & & $7(7 \%)$ \\
0 to 30 & 11 & $4(13 \%)$ & $32(31 \%)$ \\
31 to 40 & 47 & $15(50 \%)$ & $43(42 \%)$ \\
41 to 50 & 52 & $9(30 \%)$ & $20(20 \%)$ \\
51 to 70 & 22 & $2(7 \%)$ & \\
\hline
\end{tabular}

D: Dose; n: number of patients.

probability of trismus would be $33 \%$ if the dose to the contralateral mandible joint is $20 \mathrm{~Gy}$, but can be decreased to $21 \%$ and $17 \%$ if the dose is reduced to $10 \mathrm{~Gy}$ and $5 \mathrm{~Gy}$, respectively. Although there are a few reports on reducing trismus by IMRT $(38,48,49)$, no optimal dose constraints for the mandible joints have been established. Our study adds information to such RT practice.

Second, our prediction model may identify patients at high risk for developing trismus and who may benefit from a preventive exercise program early during or directly after treatment. Such rehabilitation programs are currently available for HNC patients $(5,6,50-52)$. 


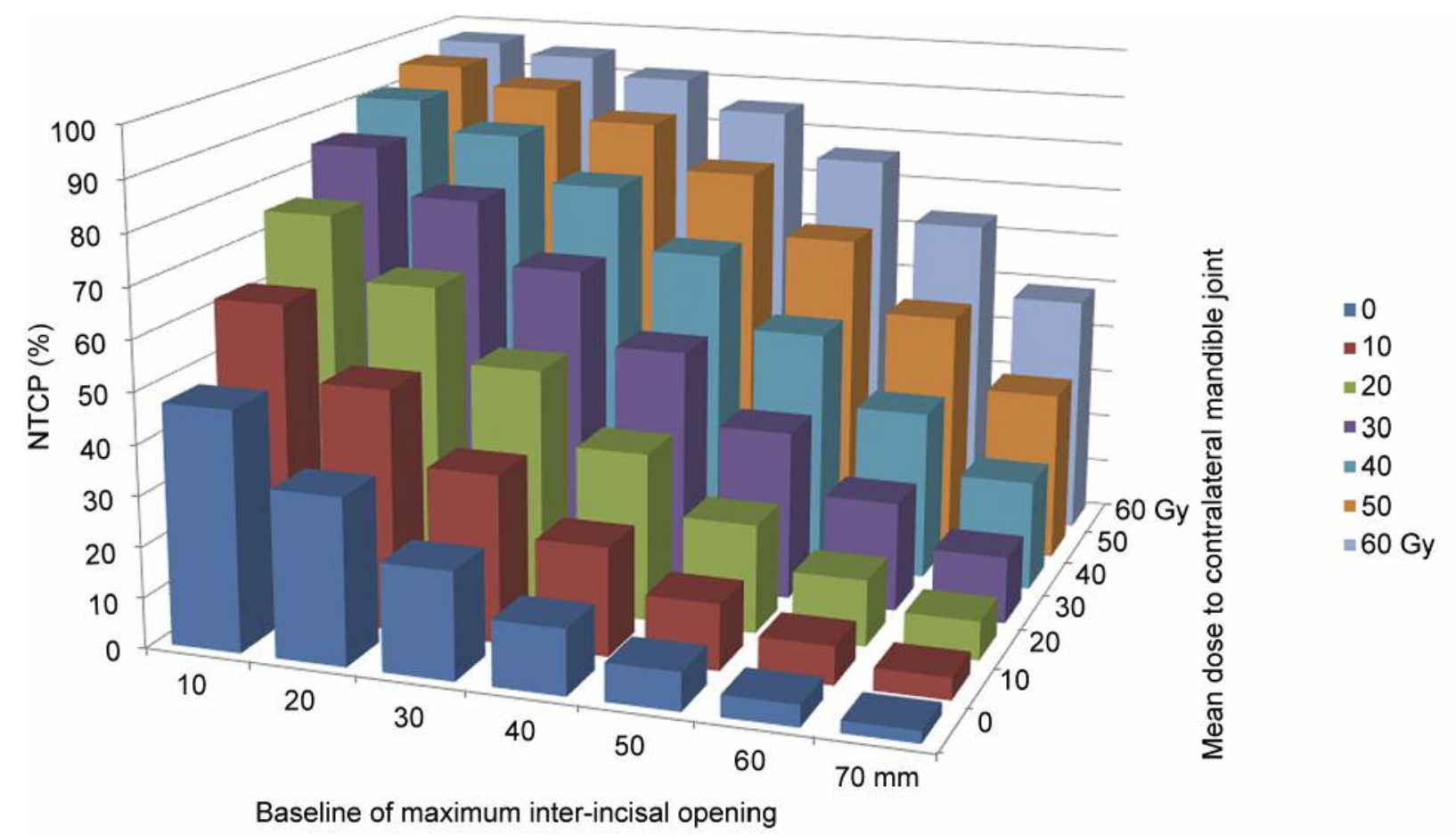

Figure 2. Normal tissue complication probability (NTCP) model for trismus in head and neck cancer patients treated with radiotherapy.

\begin{tabular}{|c|c|c|c|c|c|c|c|c|c|c|c|c|c|c|}
\hline & & & & & Mean & lose to & contral & ateral $n$ & andibli & joint & & & & \\
\hline & & 0 Gy & 5 Gy & $10 \mathrm{~Gy}$ & 15 Gy & 20 Gy & 25 Gy & 30 Gy & $35 \mathrm{G}$ & $40 \mathrm{G}$ & 45 Gy & 50 Gy & 55 Gy & 60 Gy \\
\hline 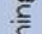 & $5 \mathrm{~mm}$ & $55 \%$ & $62 \%$ & $69 \%$ & $75 \%$ & $80 \%$ & $85 \%$ & $88 \%$ & $91 \%$ & $93 \%$ & $95 \%$ & $96 \%$ & $97 \%$ & $98 \%$ \\
\hline ळ & $10 \mathrm{~mm}$ & $47 \%$ & $55 \%$ & $62 \%$ & $69 \%$ & $75 \%$ & $81 \%$ & $85 \%$ & $88 \%$ & $91 \%$ & $93 \%$ & $95 \%$ & $96 \%$ & $97 \%$ \\
\hline $\bar{\varpi}$ & $15 \mathrm{~mm}$ & $40 \%$ & $47 \%$ & $55 \%$ & $62 \%$ & $69 \%$ & $75 \%$ & $81 \%$ & $85 \%$ & $88 \%$ & $91 \%$ & $93 \%$ & $95 \%$ & $96 \%$ \\
\hline 0 & $20 \mathrm{~mm}$ & $33 \%$ & $40 \%$ & $48 \%$ & $55 \%$ & $63 \%$ & $69 \%$ & $75 \%$ & $81 \%$ & $85 \%$ & $88 \%$ & $91 \%$ & $93 \%$ & $95 \%$ \\
\hline & $25 \mathrm{~mm}$ & $27 \%$ & $33 \%$ & $40 \%$ & $48 \%$ & $55 \%$ & $63 \%$ & $70 \%$ & $76 \%$ & $81 \%$ & $85 \%$ & $89 \%$ & $91 \%$ & $93 \%$ \\
\hline ثै & $30 \mathrm{~mm}$ & $21 \%$ & $27 \%$ & $33 \%$ & $40 \%$ & $48 \%$ & $55 \%$ & $63 \%$ & $70 \%$ & $76 \%$ & $81 \%$ & $85 \%$ & $89 \%$ & $91 \%$ \\
\hline $\bar{E}$ & $35 \mathrm{~mm}$ & $17 \%$ & $21 \%$ & $27 \%$ & $33 \%$ & $40 \%$ & $48 \%$ & $56 \%$ & $63 \%$ & $70 \%$ & $76 \%$ & $81 \%$ & $85 \%$ & $89 \%$ \\
\hline है & $40 \mathrm{~mm}$ & $13 \%$ & $17 \%$ & $21 \%$ & $27 \%$ & $33 \%$ & $41 \%$ & $48 \%$ & $56 \%$ & $63 \%$ & $70 \%$ & $76 \%$ & $81 \%$ & $85 \%$ \\
\hline 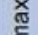 & $45 \mathrm{~mm}$ & $10 \%$ & $13 \%$ & $17 \%$ & $22 \%$ & $27 \%$ & $34 \%$ & $41 \%$ & $48 \%$ & $56 \%$ & $63 \%$ & $70 \%$ & $76 \%$ & $81 \%$ \\
\hline 4 & $50 \mathrm{~mm}$ & $8 \%$ & $10 \%$ & $13 \%$ & $17 \%$ & $22 \%$ & $27 \%$ & $34 \%$ & $41 \%$ & $48 \%$ & $56 \%$ & $63 \%$ & $70 \%$ & $76 \%$ \\
\hline 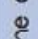 & $55 \mathrm{~mm}$ & $6 \%$ & $8 \%$ & $10 \%$ & $13 \%$ & $17 \%$ & $22 \%$ & $27 \%$ & $34 \%$ & $41 \%$ & $48 \%$ & $56 \%$ & $63 \%$ & $70 \%$ \\
\hline$\frac{1}{8}$ & $60 \mathrm{~mm}$ & $4 \%$ & $6 \%$ & $8 \%$ & $10 \%$ & $13 \%$ & $17 \%$ & $22 \%$ & $27 \%$ & $34 \%$ & $41 \%$ & $49 \%$ & $56 \%$ & $64 \%$ \\
\hline ల్ల & $65 \mathrm{~mm}$ & $3 \%$ & $4 \%$ & $6 \%$ & $8 \%$ & $10 \%$ & $13 \%$ & $17 \%$ & $22 \%$ & $28 \%$ & $34 \%$ & $41 \%$ & $49 \%$ & $56 \%$ \\
\hline & $70 \mathrm{~mm}$ & $2 \%$ & $3 \%$ & $4 \%$ & $6 \%$ & $8 \%$ & $10 \%$ & $13 \%$ & $17 \%$ & $22 \%$ & $28 \%$ & $34 \%$ & $41 \%$ & $49 \%$ \\
\hline
\end{tabular}

Figure 3. Quick reference matrix of normal tissue complication probability (NTCP) for trismus in head and neck cancer patients treated with radiotherapy.

Third, pentoxifylline, which is a suppressor of TNF $\alpha$ (9, 10 ), or microcurrent therapy may be useful to prevent or relieve trismus in the same high-risk group for developing trismus (53). To verify efficacy of the above-mentioned approach, future prospective trials are warranted.

\section{Conclusion}

We developed a multivariable prediction model for trismus, after definitive RT with or without systemic treatment for $\mathrm{HNC}$, consisting of the mean dose to contralateral mandible 
Table V. Multivariable logistic regression model for trismus.

\begin{tabular}{lccc}
\hline & $\beta$ & $p$-Value & Odds ratio \\
\hline Mean dose to contralateral mandible joint (Gy) & 0.061 & 0.001 & 1.062 \\
Baseline maximum inter-incisal opening (mm) & -0.06 & 0.027 & 0.942 \\
Constant & 0.494 & $0.893-0.993$ & \\
\hline
\end{tabular}

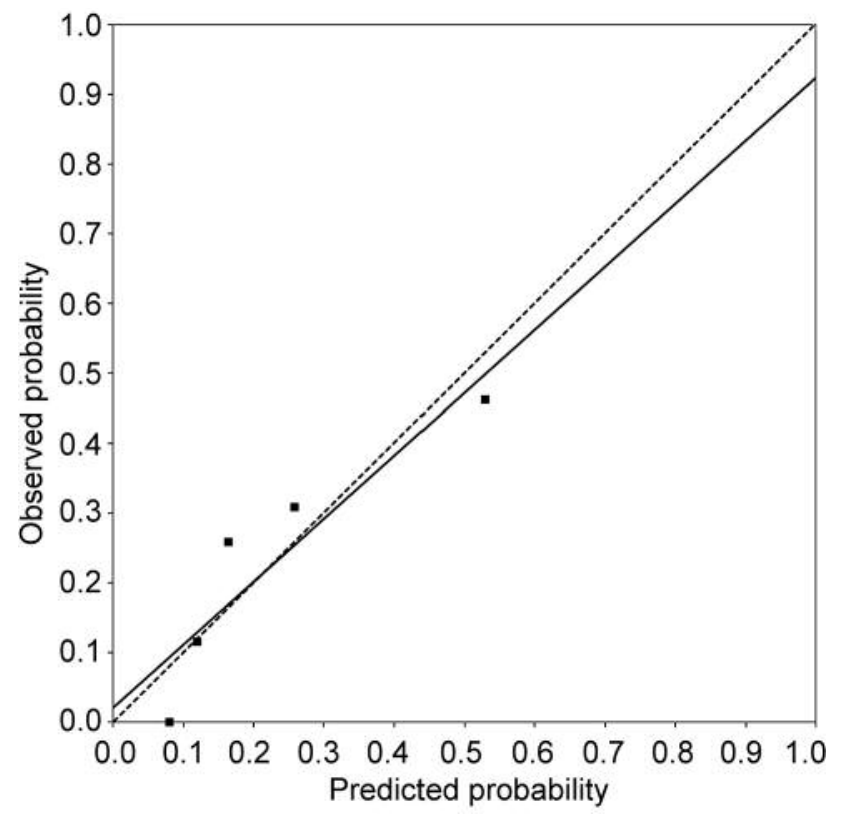

Figure 4. Calibration of a predictive model for patient-related trismus based on two prognostic factors, which were the baseline of maximum inter-incisal opening and the mean dose to contralateral mandible joint. Dashed line indicates perfect agreement. Solid line represents the fit of the observed versus the expected probability.

joint and baseline MIO. This NTCP model can be used to define dose constraint in clinical practice.

\section{Conflicts of Interest}

The are no conflicts of interest to declare regarding this study.

\section{Authors' Contributions}

Conception and design: Henk P. Bijl, Arjen van der Schaaf, and Johannes A. Langendijk. Acquisition of data: Masahiro Morimoto, Henk P. Bijl, Roel J.H.M. Steenbakkers, Olga Chouvalova, and Johannes A. Langendijk. Analysis and interpretation of data: Masahiro Morimoto, Henk P. Bijl, Arjen van der Schaaf, Cheng-Jian $\mathrm{Xu}$, Yasuo Yoshioka, Teruki Teshima, and Johannes A. Langendijk. Writing, review, and/or revision of the manuscript: Masahiro Morimoto, Yasuo Yoshioka, and Johannes A. Langendijk.

\section{Acknowledgements}

This work was supported by a grant of the European Union (ALLEGRO-project), the Japan Society for Promotion Science (JSPS) Core-to-Core Program (number 23003) and JSPS KAKENHI Grant Number 18K15616.

\section{References}

1 Pauli N, Johnson J, Finizia C and Andréll P: The incidence of trismus and long-term impact on health-related quality of life in patients with head and neck cancer. Acta Oncol 52: 11371145, 2013. PMID: 23193958. DOI: 10.3109/0284186 X.2012.744466

2 Lee R, Slevin N, Musgrove B, Swindell R and Molassiotis A: Prediction of post-treatment trismus in head and neck cancer patients. Br J Oral Maxillofac Surg 50: 328-332, 2012. PMID: 21794962. DOI: 10.1016/j.bjoms.2011.06.009

3 Scott B, Butterworth C, Lowe D and Rogers SN: Factors associated with restricted mouth opening and its relationship to health-related quality of life in patients attending a Maxillofacial Oncology clinic. Oral Oncol 44: 430-438, 2008. PMID: 17826305. DOI: 10.1016/j.oraloncology.2007.06.015

4 Payakachat N, Ounpraseuth S and Suen JY: Late complications and long-term quality of life for survivors ( $>5$ years) with history of head and neck cancer. Head Neck 35: 819-825, 2013. PMID: 22807083. DOI: 10.1002/hed.23035

5 Tang Y, Shen Q, Wang Y, Lu K, Wang Y and Peng Y: A randomized prospective study of rehabilitation therapy in the treatment of radiation-induced dysphagia and trismus. Strahlenther Onkol 187: 39-44, 2011. PMID: 21136031. DOI: 10.1007/s00066-010-2151-0

6 Buchbinder D, Currivan RB, Kaplan AJ and Urken ML: Mobilization regimens for the prevention of jaw hypomobility in the radiated patient: a comparison of three techniques. J Oral Maxillofac Surg 51: 863-867, 1993. PMID: 8336223. DOI: 10.1016/s0278-2391(10)80104-1

7 Kamstra JI, van Leeuwen M, Roodenburg JLN and Dijkstra PU: Exercise therapy for trismus secondary to head and neck cancer: A systematic review. Head Neck 39: 2352-2362, 2017. PMID: 26876238. DOI: 10.1002/hed.24859

8 Loorents V, Rosell J, Karlsson C, Lidbäck M, Hultman K and Börjeson S: Prophylactic training for the prevention of radiotherapy-induced trismus - a randomised study. Acta Oncol 53: 530-538, 2014. PMID: 24635110. DOI: 10.3109/028418 6X.2014.892211

9 Okunieff P, Augustine E, Hicks JE, Cornelison TL, Altemus RM, Naydich BG, Ding I, Huser AK, Abraham EH, Smith JJ, 
Coleman $\mathrm{N}$ and Gerber LH: Pentoxifylline in the treatment of radiation-induced fibrosis. J Clin Oncol 22: 2207-2213, 2004. PMID: 15169810. DOI: 10.1200/JCO.2004.09.101

10 Chua DT, Lo C, Yuen J and Foo YC: A pilot study of pentoxifylline in the treatment of radiation-induced trismus. Am J Clin Oncol 24: 366-369, 2001. PMID: 11474263. DOI: 10.1097/00000421-200108000-00010

11 Stubblefield MD: Radiation fibrosis syndrome: neuromuscular and musculoskeletal complications in cancer survivors. PM R 3: 1041-1054, 2011. PMID: 22108231. DOI: 10.1016/j.pmrj. 2011.08.535

12 Teguh DN, Levendag PC, Voet P, van der Est H, Noever I, de Kruijf W, van Rooij P, Schmitz PI and Heijmen BJ: Trismus in patients with oropharyngeal cancer: relationship with dose in structures of mastication apparatus. Head Neck 30: 622-630, 2008. PMID: 18213726. DOI: 10.1002/hed.20760

13 Goldstein M, Maxymiw WG, Cummings BJ and Wood RE: The effects of antitumor irradiation on mandibular opening and mobility: a prospective study of 58 patients. Oral Surg Oral Med Oral Pathol Oral Radiol Endod 88: 365-373, 1999. PMID: 10503870. DOI: 10.1016/s1079-2104(99)70044-2

14 Gebre-Medhin M, Haghanegi M, Robert L, Kjellen E and Nilsson P: Dose-volume analysis of radiation-induced trismus in head and neck cancer patients. Acta Oncol 55:1313-1317, 2016. PMID: 27595312. DOI: 10.1080/0284186X.2016.1221129

15 Rao SD, Saleh ZH, Setton J, Tam M, McBride SM, Riaz N, Deasy JO and Lee NY: Dose-volume factors correlating with trismus following chemoradiation for head and neck cancer. Acta Oncol 55: 99-104, 2016. PMID: 25920361. DOI: 10.3109/0284186X.2015.1037864

16 Lindblom U, Gärskog O, Kjellén E, Laurell G, Levring Jäghagen E, Wahlberg P, Zackrisson B and Nilsson P: Radiation-induced trismus in the ARTSCAN head and neck trial. Acta Oncol 53: 620-627, 2014. PMID: 24669774. DOI: $0.3109 / 0284186$ X.2014.892209

17 van der Molen L, Heemsbergen WD, de Jong R, van Rossum MA, Smeele LE, Rasch CR and Hilgers FJ: Dysphagia and trismus after concomitant chemo-Intensity-Modulated Radiation Therapy (chemo-IMRT) in advanced head and neck cancer; dose-effect relationships for swallowing and mastication structures. Radiother Oncol 106: 364-369, 2013. PMID: 23540551. DOI: $10.1016 /$ j.radonc.2013.03.005

18 Beasley W, Thor M, McWilliam A, Green A, Mackay R, Slevin N, Olsson C, Pettersson N, Finizia C, Estilo C, Riaz N, Lee NY, Deasy JO and van Herk M: Image-based data mining to probe dosimetric correlates of radiation-induced trismus. Int J Radiat Oncol Biol Phys 15口1330-1338, 2018. PMID: 30061005. DOI: 10.1016/j.ijrobp.2018.05.054

19 Hague C, Beasley W, Garcez K, Lee LW, McPartlin A, McWilliam A, Ryder D, Sykes AJ, Thomson D, van Herk M, West C and Slevin NJ: Prospective evaluation of relationships between radiotherapy dose to masticatory apparatus and trismus. Acta Oncol 57: 1038-1042, 2018. PMID: 29630433. DOI: 10.1080/0284186X.2018.1459047

20 Kraaijenga SA, Hamming-Vrieze O, Verheijen S, Lamers E, van der Molen L, Hilgers FJ, van den Brekel MW and Heemsbergen WD: Radiation dose to the masseter and medial pterygoid muscle in relation to trismus after chemoradiotherapy for advanced head and neck cancer. Head Neck 41: 1387-1394, 2019. PMID: 30652390. DOI: 10.1080/0284186X.2018.1459047
21 Christianen ME, Schilstra C, Beetz I, Muijs CT, Chouvalova O, Burlage FR, Doornaert P, Koken PW, Leemans CR, Rinkel RN, de Bruijn MJ, de Bock GH, Roodenburg JL, van der Laan BF, Slotman BJ, Verdonck-de Leeuw IM, Bijl HP and Langendijk JA: Predictive modelling for swallowing dysfunction after primary (chemo)radiation: results of a prospective observational study. Radiother Oncol 105: 107-114, 2012. PMID: 21907437. DOI: 10.1016/j.radonc.2011.08.009

22 Bashiri H and Suen JY: Dental consideration. In: Myers EN, Suen JY, editors. Cancer of the Head and Neck. 2nd Edition, New York: Churchill-Livingstone Inc. pp. 179-196, 1989.

23 Dijkstra PU, Huisman PM and Roodenburg JL: Criteria for trismus in head and neck oncology. Int J Oral Maxillofac Surg 35: 337-342, 2006. PMID: 16280237. DOI: 10.1016/j.ijom.2005.08.001

24 Wang CJ, Huang EY, Hsu HC, Chen HC, Fang FM and Hsiung CY: The degree and time-course assessment of radiation-induced trismus occurring after radiotherapy for nasopharyngeal cancer. Laryngoscope 115: 1458-1460, 2005. PMID: 16094124. DOI: 10.1097/01.mlg.0000171019.80351.46

25 Langendijk JA, Leemans CR, Buter J, Berkhof J and Slotman BJ: The additional value of chemotherapy to radiotherapy in locally advanced nasopharyngeal carcinoma: a meta-analysis of the published literature. J Clin Oncol 22: 4604-4612, 2004. PMID: 15542811. DOI: 10.1200/JCO.2004.10.074

26 Pignon JP, le Maître A, Maillard E and MACH-NC Collaborative Group: Meta-analysis of chemotherapy in head and neck cancer (MACH-NC): an update on 93 randomised trials and 17,346 patients. Radiother Oncol 92: 4-14, 2009. PMID: 21684027. DOI: 10.1016/j.radonc.2011.05.036

27 Bonner JA, Harari PM, Giralt J, Cohen RB, Jones CU, Sur RK, Raben D, Baselga J, Spencer SA, Zhu J, Youssoufian H, Rowinsky EK and Ang KK: Radiotherapy plus cetuximab for locoregionally advanced head and neck cancer: 5-year survival data from a phase 3 randomised trial, and relation between cetuximab-induced rash and survival. Lancet Oncol 11: 21-28, 2010. PMID: 19897418. DOI: 10.1016/S1470-2045(09)70311-0

28 Liu XQ, Luo W, Tang YQ, He ZC, Sun Y, Ma J, Lu TX and Liu MZ: A matched cohort analysis of three-dimensional conformal radiotherapy versus conventional radiotherapy for primary nasopharyngeal carcinoma. Ai Zheng 27: 606-611, 2008. PMID: 18570734.

29 Tonoli S, Magrini SM, Costa L, Paiar F, Simontacchi G, Scotti V, Pasinetti N, Barca R, Barbieri D, De Stefani A, Cellai E, Buglione $\mathrm{M}$ and Biti G: A benchmark study on 883 nasopharyngeal cancer patients treated in two Italian centres from 1977 to 2000. Part I: Evolving technical choices and survival. Radiol Med 117: 690-714, 2012. PMID: 22095424. DOI: $10.1007 / \mathrm{s} 11547-011-0755-9$

30 Hodge CW, Bentzen SM, Wong G, Palazzi-Churas KL, Wiederholt PA, Gondi V, Richards GM, Hartig GK and Harari PM: Are we influencing outcome in oropharynx cancer with intensity-modulated radiotherapy? An inter-era comparison. Int J Radiat Oncol Biol Phys 69: 1032-1041, 2007. PMID: 17967300. DOI: 10.1016/j.ijrobp.2007.05.017

31 Langendijk JA, Doornaert P, Verdonck-de Leeuw IM, Leemans CR, Aaronson NK and Slotman BJ: Impact of late treatment-related toxicity on quality of life among patients with head and neck cancer treated with radiotherapy. J Clin Oncol 26: 3770-3776, 2008. PMID: 18669465. DOI: $10.1200 / J C O .2007 .14 .6647$ 
32 Jellema AP, Slotman BJ, Doornaert P, Leemans CR and Langendijk JA: Impact of radiation-induced xerostomia on quality of life after primary radiotherapy among patients with head and neck cancer. Int J Radiat Oncol Biol Phys 69: 751-760, 2007. PMID: 17560735. DOI: 10.1016/j.ijrobp.2007.04.021

33 Beetz I, Burlage FR, Bijl HP, Hoegen-Chouvalova O, Christianen ME, Vissink A, van der Laan BF, de Bock GH and Langendijk JA: The Groningen Radiotherapy-Induced Xerostomia questionnaire: development and validation of a new questionnaire. Radiother Oncol 97: 127-131, 2010. PMID: 20541272. DOI: $10.1016 /$ j.radonc .2010 .05 .004

34 Ichimura $\mathrm{K}$ and Tanaka $\mathrm{T}$ : Trismus in patients with malignant tumours in the head and neck. J Laryngol Otol 107: 1017-1020, 1993. PMID: 8288970. DOI: 10.1017/s0022215100125149

35 Johnson J, van As-Brooks CJ, Fagerberg-Mohlin B and Finizia $\mathrm{C}$ : Trismus in head and neck cancer patients in Sweden: incidence and risk factors. Med Sci Monit 16: CR278-282, 2010. PMID: 20512090.

36 Dijkstra PU, Kalk WW and Roodenburg JL: Trismus in head and neck oncology: a systematic review. Oral Oncol 40: 879-889, 2004. PMID: 15380165. DOI: 10.1016/j.oraloncology.2004.04.003

37 Weber C, Dommerich S, Pau HW and Kramp B: Limited mouth opening after primary therapy of head and neck cancer. Oral Maxillofac Surg 14: 169-173, 2010. PMID: 20358238. DOI: 10.1007/s10006-010-0220-2

38 Louise Kent M, Brennan MT, Noll JL, Fox PC, Burri SH, Hunter JC and Lockhart PB: Radiation-induced trismus in head and neck cancer patients. Support Care Cancer 16: 305-309, 2008. PMID: 17965892. DOI: 10.1007/s00520-007-0345-5

39 Chen YY, Zhao C, Wang J, Ma HL, Lai SZ, Liu Y, Han F, Lu LX, Bao $\mathrm{Y}$ and Chen $\mathrm{M}$ : Intensity-modulated radiation therapy reduces radiation-induced trismus in patients with nasopharyngeal carcinoma: a prospective study with $>5$ years of follow-up. Cancer 117: 2910-2916, 2011. PMID: 21264821. DOI: 10.1002/cncr.25773

40 Pauli N, Johnson J, Finizia C and Andréll P: The incidence of trismus and long-term impact on health-related quality of life in patients with head and neck cancer. Acta Oncol 52: 1137-1145, 2013. PMID: 23193958. DOI: 10.3109/0284186X.2012.744466

41 Astradsson T, Laurell G, Ahlberg A, Nikolaidis P, Johansson H and Ehrsson YT: Trismus in patients with head and neck cancer and 5-year overall survival. Acta Otolaryngol 138: 1123-1127, 2018. PMID: 30686104. DOI: 10.1080/00016489.2018.1511059

42 Watters AL, Cope S, Keller MN, Padilla M and Enciso R: Prevalence of trismus in patients with head and neck cancer: A systematic review with meta-analysis. Head Neck 41: 34083421, 2019. PMID: 31215723. DOI: 10.1002/hed.25836

43 van der Geer SJ, van Rijn PV, Kamstra JI, Langendijk JA, van der Laan BFAM, Roodenburg JLN and Dijkstra PU: Prevalence and prediction of trismus in patients with head and neck cancer: A cross-sectional study. Head Neck 41: 64-71, 2019. PMID: 30561067. DOI: 10.1002/hed.25369
44 Ito T: Head and neck. In: Human Anatomy. Ito T (ed.). Tokyo: Nanzando Inc. pp. 510-512, 1998.

45 Bhatia KS, King AD, Paunipagar BK, Abrigo J, Vlantis AC, Leung SF and Ahuja AT: MRI findings in patients with severe trismus following radiotherapy for nasopharyngeal carcinoma. Eur Radiol 19: 2586-2593, 2009. PMID: 19504110. DOI: 10.1007/s00330-009-1445-Z

46 Kamstra JI, Dijkstra PU, van Leeuwen M, Roodenburg JL and Langendijk JA: Mouth opening in patients irradiated for head and neck cancer: a prospective repeated measures study. Oral Oncol 51: 548-555, 2015. PMID: 25703798. DOI: 10.1016/j.oraloncology.2015.01.016

47 van der Geer SJ, Kamstra JI, Roodenburg JL, van Leeuwen M, Reintsema H, Langendijk JA and Dijkstra PU: Predictors for trismus in patients receiving radiotherapy. Acta Oncol 55: 13181323, 2016. PMID: 27627138. DOI: 10.1080/028 4186X.2016.1223341

48 Bensadoun RJ, Riesenbeck D, Lockhart PB, Elting LS, Spijkervet FK and Brennan MT: A systematic review of trismus induced by cancer therapies in head and neck cancer patients. Support Care Cancer 18: 1033-1038, 2010. PMID: 20213237. DOI: $10.1007 / \mathrm{s} 00520-010-0847-4$

49 Hsiung CY, Huang EY, Ting HM and Huang HY: Intensitymodulated radiotherapy for nasopharyngeal carcinoma: the reduction of radiation-induced trismus. Br J Radiol 81: 809-814, 2008. PMID: 18591201. DOI: 10.1259/bjr/17942449

50 Melchers LJ, Van Weert E, Beurskens CH, Reintsema H, Slagter AP, Roodenburg JL and Dijkstra PU: Exercise adherence in patients with trismus due to head and neck oncology: a qualitative study into the use of the Therabite. Int $\mathrm{J}$ Oral Maxillofac Surg 38: 947-954, 2009. PMID: 19414238. DOI: 10.1016/j.ijom.2009.04.003

51 Dijkstra PU, Sterken MW, Pater R, Spijkervet FK and Roodenburg JL: Exercise therapy for trismus in head and neck cancer. Oral Oncol 43: 389-394, 2007. DOI: 10.1016/j.oraloncology.2006.04.003

52 Pauli N, Svensson U, Karlsson $\mathrm{T}$ and Finizia C: Exercise intervention for the treatment of trismus in head and neck cancera prospective two-year follow-up study. Acta Oncol 55: 686-692, 2016. PMID: 26878553. DOI: 10.3109/0284186X.2015.1133928

53 Lennox AJ, Shafer JP, Hatcher M, Beil J and Funder SJ: Pilot study of impedance-controlled microcurrent therapy for managing radiation-induced fibrosis in head-and-neck cancer patients. Int J Radiat Oncol Biol Phys 54: 23-34, 2002. PMID: 12182971. DOI: 10.1016/s0360-3016(02)02898-5

Received October 18, 2019

Revised November 6, 2019

Accepted November 7, 2019 